\title{
Fronteira-Sul: O Arquivo da Exterioridade ${ }^{1}$
}

\author{
Fronteira-Sul: El Arquivo de la Exterioridad \\ Fronteira-Sul: The Archive of the Exteriority
}

Edgar Cézar Nolasco ${ }^{2}$

\begin{abstract}
Resumo
Tendo como lócus delimitado a fronteira-sul que faz divisa com os países Paraguai e Bolívia, o trabalho propõe uma discussão de base conceitual que privilegia, entre outros conceitos, os de exterioridade, fronteira, razão subalterna e gnose liminar, entre outros, por entender que tais conceitos são fundamentais para uma discussão que tem como preocupação maior um lócus fronteiriço, cuja realidade apresenta-se como um lugar "pós-abissal" por meio do qual atravessa a condição de sofrimento humano dos que ali vivem. Para a discussão proposta, foram essenciais os apontamentos críticos descoloniais feitos por Walter Mignolo, Boaventura de Sousa Santos, entre outros que partilham, inclusive, de abordagens diferentes, como Jacques Derrida com sua discussão acerca do conceito de arquivo.
\end{abstract}

Palavras-Chave: Crítica biográfica fronteiriça; Descolonialidade; Fronteira-sul; Exterioridade; Razão subalterna

\section{Resumen}

El trabajo propone una discusión de base conceptual que privilegia, entre otros conceptos, los de exterioridad, frontera, razón subalterna y gnosis liminar, entre otros, por entender que tales conceptos son fundamentales para una discusión que tiene como preocupación mayor un locus fronterizo, cuya realidad se presenta como un lugar "post-abisal" por medio del cual atraviesa la condición de sufrimiento humano de los que allí viven. Para la discusión propuesta, fueron esenciales los apuntes críticos descoloniales hechos por Walter Mignolo, Boaventura de Sousa Santos, entre otros que comparten, incluso, de enfoques diferentes, como Jacques Derrida con su discusión acerca del concepto de archivo.

Palabras claves: Crítica biográfica fronteiriça; Descolonialidad; Exterioridad; Frontera-sul; Razon subalterna

\begin{abstract}
Taking as a delimited locus the southern frontier that borders the countries of Paraguay and Bolivia, the paper proposes a conceptual discussion which privileges, among other concepts, those of exteriority, frontier, subaltern reason and gnosis, among others, for understand that such concepts are fundamental to a discussion that has as its main concern a frontier locus, whose reality presents itself as a "post-abyssal" place through which it crosses the condition of human suffering of those who live there. For the proposed discussion the critical decolonial notes made by Walter Mignolo, Boaventura de Sousa Santos, among others are essential. They even share different approaches, such as Jacques Derrida, whom the discussion about the concept of archive, were essential to this work.
\end{abstract}

Keywords: Crítica biográfica fronteiriça; Dsscoloniality, Exteriority, Southern frontier, Subaltern Reason

\footnotetext{
1 Artigo apresentado no Simpósio Temático (Fronteiras Culturais em Contextos Epistêmicos Descoloniais II) durante o II Seminário Latino-Americano de Estudos em Cultura - SEMLACult em Foz do Iguaçu/PR, Brasil, 2018.

2 (Doutorado em Literatura Comparada pela Universidade Federal de Minas Gerais (2003); Universidade Federal do Mato Grosso do Sul - UFMS; Campo Grande, Mato Grosso do Sul, Brasil; ecnolasco@uol.com.br.
} 
El pensamento fronterizo es la condición necesaria para que existan los proyectos de la desoccidentalización y la descolonialidad. Sin embargo, ambos difieren radicalmente en sus objetivos respectivos. Y es condición necesaria porque afirmar la desoccidentalización implica pensar y argumentar en situación de exterioridad com respecto a la propia occidentalización moderna. La exterioridad no es un afuera del capitalismo y de la civilización occidental, sino el afuera que se crea en el processo de crear el adentro: el entramado del espacio que crea la diferencia imperial (de donde surge básicamente la desoccidentalización) y de la diferencia colonial (de donde surge básicamente la descolonialidad). El adentro de la modernidade occidental há sido construido desde el Renacimiento, basado en la doble, simultânea y continua colonización del espacio y del tiempo. (MIGNOLO, 2015, p. 187).

\title{
1. Narrativas da memória: exterioridade do bios (O intelectual Silviano Santiago a exemplo)
}

\begin{abstract}
Hoje diríamos que mais que "nos modernizar" a orientação é para "nos naturalizar". Isto é, na medida em que o discurso constitutivo da modernidade separou ser humano e natureza, cultura e natureza, e nos fez esquecer que somos (nossos corpos necessitam de água e alimentos) natureza. Por isso, a tendência hoje é a de naturalizar-nos mais que nos modernizar. (MIGNOLO, 2017, p. 26).
\end{abstract}

A passagem que abre este ensaio ilustra, mais do que metaforicamente, a discussão que proponho acerca das narrativas da memória fronteiriça, as quais se encontram arquivadas na exterioridade do pensamento colonial moderno:

Quando Frantz Fanon termina seu Pele negra, máscaras brancas com uma prece: "Oh corpo meu, faz de mim, sempre, um homem que se interrogue!" (1973, p. 192) expressou, em uma só frase, as categorias básicas da epistemologia fronteiriça: a percepção bio-gráfica do corpo Negro no Terceiro Mundo, fundando assim uma política do conhecimento que está arraigada, assim como o corpo racializado, nas histórias locais marcadas pela colonialidade. (MIGNOLO, 2017, p.16).

Quero, depois, deter-me nessas categorias básicas da epistemologia fronteiriça, especificamente visando pontuar a presença do corpo do intelectual no Terceiro Mundo, ou melhor, nas narrativas da memória fronteiriça, e como esse corpo na/da diferença funda uma política do conhecimento específica e, ao mesmo tempo, se inscreve nas histórias ou memórias locais ignoradas pelo pensamento moderno colonial. Antes, porém, entendo que devo me deter em conceitos que são fundamentais para a discussão aqui proposta, como os já mencionados Arquivo, exterioridade, epistemologia fronteiriça, memória e ou história local, opção descolonial, desobediência epistêmica, entre outros que forem aparecendo no decorrer da discussão.

Começo pelo arquivo, pelo conceito e pela palavra, na tentativa de querer abrir o arquivo da exterioridade, se é que é possível abrir tal arquivo, falar dele, ou só se pode falar a 
partir dele, de-dentro dele, como assim o devemos fazer diante do próprio pensamento fronteiriço. No texto de Mignolo antes citado, Desafios decoloniais hoje, ao tratar da genealogia do pensamento fronteiriço, o autor comenta em nota que "não é apenas um problema dos nativos americanos como às vezes ouço as pessoas dizerem após minhas palestras. Intelectuais críticos de todo o mundo estão conscientes dos limites dos arquivos ocidentais.”. (MIGNOLO. 2017, p. 21.) Abro um parêntese aqui para inserir o intelectual crítico e escritor brasileiro Silviano Santiago, por entender que ele, por meio de sua crítica e de sua ficção, ao invés de endossar o arquivo ocidental moderno, propõe a abertura de um arquivo outro que consigna sujeitos, narrativas e memórias que se encontram na exterioridade do arquivo da tradição moderna. ${ }^{3}$

É nesse sentido que a narrativa memorialística do escritor mineiro vai ilustrar a discussão aqui feita. Derrida abre o seu Mal de arquivo (2001) se perguntado "por que reelaborar hoje um conceito de arquivo?”“4 (DERRIDA, 2001, p. 7), e adverte inicialmente que "os desastres que marcam o fim do milênio são também arquivos do mal: dissimulados ou destruídos, interditados, desviados, 'recalcados"”. (DERRIDA. 2001, p. 7). Ressalvadas todas as diferenças que possam haver entre o contexto do qual fala Derrida e o contexto dentro do qual me encontro pensando acerca do arquivo hoje, quero entender que as coisas, em nível mundial, não mudaram muito, talvez tenham apenas se agravado ainda mais: haja vista a condição de refugiados que tomou conta do mundo presente; e, para não ir muito longe de nossa realidade, basta lembrar das condições sub-humanas nas quais se encontram os venezuelanos no Norte do país. Pergunto: como abrir esse arquivo do mal, se é que podemos abri-lo, como falar dessa exterioridade criada pela própria interioridade do mundo ocidental moderno?

Reconheço que, apesar de partir aqui de Derrida, sua discussão parece não encampar esse conceito de arquivo da exterioridade que busco, por tratar-se de um arquivo descolonial, fronteiriço, ex-cêntrico, enquanto seu conceito de arquivo padece de um mal de arquivo radical e moderno. Todavia reconheço também que a exterioridade da qual fala o filósofo pode ser o ponto de partida para a discussão que busco. "Exterioridade de um lugar" (DERRIDA, 2001, p. 8), afirma ele, "tal seria a condição do arquivo" (DERRIDA, 2001, p.

\footnotetext{
3 "Eu sou disciplinado, mas não sou disciplinar. Sou um leitor dos autores canônicos, mas não sou nada canônico. Eu sou um equilibrista. Eu me desequilíbrio se persisto no tradicional", p. 40 (Entrevista "Silviano, o equilibrista, com José Castello. Revista OLYMPIO, 2018)

${ }^{4}$ Lembro que a Conferência que resultou no livro Mal de arquivo (1995) foi proferida no dia 5 de junho de 1994, em Londres, por ocasião de um colóquio internacional intitulado: Memória: a questão dos arquivos, e o título inicial desta conferência foi $O$ conceito de arquivo. Uma impressão freudiana.
} 
8). Se, conforme diz Derrida, "Mal de arquivo evoca sem dúvida um sintoma, um sofrimento, uma paixão: o arquivo do mal; mas também aquilo que arruína, desvia ou destrói o próprio princípio do arquivo, a saber, o mal radical” (DERRIDA, 2001, p. 9), o arquivo da exterioridade, por sua vez, evoca a possibilidade de uma epistemologia outra, como forma de melhor nos aproximar e tratar do que se encontra "esquecido" dentro dele, visando tratar daquilo que foi deliberadamente criado pela interioridade do pensamento ocidental moderno, a exemplo das narrativas das memórias subalternas e das histórias locais enterradas vivas no mundo sombrio da exterioridade. ${ }^{5}$ Apesar de estar falando falando em arquivo da exterioridade, quero tratar primeiro do conceito de arquivo, como já disse, e só depois falar do conceito de exterioridade, mesmo sabendo que aqui uma palavra implica a outra. Trata-se de uma escolha meramente didática, até certo ponto: pois vou me apropriando e relendo meio pelo avesso o conceito de arquivo a partir de Mal de arquivo, enquanto que o conceito de exterioridade eu simplesmente não o encontro em Derrida. Começa por nos lembrar que a palavra originária de arquivo - Arkhê - "designa ao mesmo tempo o começo e o comando" (DERRIDA, 2001, p. 9), ali onde as coisas começam e ali onde os homens e os deuses

${ }^{5}$ Como já disse, já tive a oportunidade de ler e de discutir a leitura de Mal de arquivo, quando tratei das MEMÓRIAS SUBALTERNAS LATINAS: um ensaio biográfico, p. 132-159. Ali eu dizia: "Para exumar as memórias subalternas é preciso abrir o arquivo do período colonial moderno. Daí a importância de voltar ao começo. Na verdade, começos, pois se a origem das memórias subalternas dá-se com a estruturação do sistema colonial moderno, a palavra arquivo, por sua vez, traz desde sua origem grega (Arkhê) a ideia de começo. Segundo Derrida, em Mal de arquivo, "[...] a palavra arquivo designa ao mesmo tempo o começo e o comando, ali onde as coisas começam" (DERRIDA, 2001, p. 20). Se, por um lado, a memória colonial comandava as demais memórias, vindo, inclusive, a hospedar-se em casa-arquivo das anfitriãs com o único objetivo de angariar mais poder em torno de sua história moderna da memória, consignando (in-corpo-rando) aparentemente as memórias e histórias subalternas em um grande e único corpus, por outro, as memórias subalternas, enquanto sofredoras de um mal de arquivo e de falta de memória radical, propuseram-se à tarefa de destruir toda e qualquer ideia de arquivo. Se o arquivo não está para a memória nem para a anamnese, como postula Derrida, então se pode perguntar se o arquivo das memórias subalternas "têm lugar em lugar da falta originária e estrutural da chamada memória." (DERRIDA, ANO, p. 20)? Também me parece que não, já que as memórias subalternas sobrevivem dentro de um arquivo também ignorado pelas memórias vindas de fora. As memórias vindas dos grandes centros, do ocidente, modernas por excelência, consignam e amalgamam as memórias menores em seu arquivo, exercendo, assim, compulsão à repetição por meio de sua pulsão de morte que não faz outra coisa senão destruir as memórias anfitriãs. Destruir aqui é correlato a um arquivamento sem precedente na história do ocidente, uma vez que tal arquivamento leva a um esquecimento letal das memórias subalternas. Uma epistemologia moderna, como a encontrada na leitura que sustenta a discussão proposta por Derrida em Mal de arquivo, assentada na história grega, simplesmente não atinge o arquivo que contempla as memórias latinas. Apenas uma epistemologia outra, que aprendeu a escutar o balbucio das memórias enterradas vivas e das histórias locais, por se erigir também de uma zona de fronteira, pode abrir o arquivo das memórias mal contadas pelo outro. Se as memórias subalternas, por um lado, não sofrem da falta de arquivo, sofrem, por outro, do mal de arquivo radical. Mais do que saber disso, compete ao estudioso dessas pós-memórias subalternas visar abrir o arquivo oprimido para que tais memórias saiam de seu letárgico esquecimento e ocupem seu lugar de direito na cultura do presente. (NOLASCO, 2013, p. 141-142.) 
comandam, enquanto o sentido único de arquivo vem do arkhéion grego: "inicialmente uma casa, um domicílio, um endereço, a residência dos magistrados superiores, os arcontes, aqueles que comandavam”. (DERRIDA, 2011, p. 12). E em sendo os arcontes os primeiros guardiões do arquivo, "cabia a eles o direito e a competência hermenêuticos" (DERRIDA, 2001, p. 12). Trazendo essa reflexão para o arquivo da exterioridade, diria que nele está o começo e a razão da exclusão por parte do arquivo ocidental moderno, o arquivo dos sujeitos excluídos é correlato a um mundo deliberadamente ignorado pelos deuses (homens) e guardiões do pensamento moderno, que depositaram na escuridão do fora tudo o que esse pensamento mesmo construiu para ser colonizando e eliminado. Talvez como resquício maior dessa autoridade que preserva e comanda o poder sobre o direito e a competência hermenêuticos sobre o outro, tenha prevalecido no ocidente a soberania de uma epistemologia moderna que guarda sua interioridade, que totaliza e homogeneíza as diferenças coloniais, não permitindo que epistemologias outras grassem no mundo. Se coube tão somente aos guardiões do saber moderno interpretar o arquivo (pensamento) moderno, reafirmo eu agora que cabe aos sujeitos excluídos o direito epistêmico de interpretar o arquivo da exterioridade, uma vez que este sujeito provocou uma desobediência epistêmica e assumiu uma opção descolonial criando, por conseguinte, uma epistemologia fronteiriça cuja única perspectiva é a que permite olhar de-dentro de tal arquivo. Aliás, e não por acaso, lemos em Mignolo que é do "habitar a exterioridade que surge a epistemologia como método de pensar descolonial" (MIGNOLO, 2010, p. 44). ${ }^{6}$ Nessa direção, entendo que a ideia de "anamnese autobiográfica" (DERRIDA, 2001, p.20) discutida por Derrida a partir de Freud pode me ajudar a pensar a condição do sujeito fronteiriço e do arquivo da exterioridade. Se, num primeiro momento, o sujeito fronteiriço fora deliberadamente lançado (criado) pelo arquivo/sujeito/pensamento moderno para o campo do fora, do esquecimento, da ignorância absoluta, num segundo momento e como consequência, esse sujeito da exclusão se vale de uma anamnese biográfica e por meio desse gesto rememorativo do não-esquecimento gradativo põe-se a narrar suas histórias locais que não deixam de soar como um balbucio de vida que remete a verdades essenciais, biográficas e latentes que remontam a um tempo anterior, inclusive, ao de sua existência como sujeito que ocupa a morada da exterioridade por excelência no mundo. $\mathrm{O}$ arquivo da exclusão tornou-se um mundo real diante da força e do poder do sistema colonizante do pensamento moderno ocidental. Daí poder dizer que o que vale para o conceito

\footnotetext{
6 "de habitar la exterioridad, surge la epistemologia fronteriza como método del pensar descolonial..." (MIGNOLO. (2010 p. 44-45) Mais pra frente, ao me deter no conceito de exterioridade, voltarei a essa discussão acerca de "habitar a exterioridade", e o farei a partir do livro Habitar la frontera, de Mignolo.
} 
de arquivo moderno de Derrida não vale para o arquivo da exterioridade: "o arquivo tem lugar em lugar da falta originária e estrutural da chamada memória." (DERRIDA, 2011, p. 43-44). $\mathrm{O}$ arquivo descolonial é o lugar das memórias fronteiriças por excelência, que existem e têm representação, desde que não contempladas pelo discurso do pensamento memorialístico moderno. Se, como postula Derrida, "não há arquivo sem um lugar de consignação, sem uma técnica de repetição e sem uma certa exterioridade" (2001, p. 22), logo, resta ao arquivo da exterioridade romper com tais práticas, inclusive, e principalmente, com sua condição de exterioridade, uma vez que esta foi determinada, criada, imposta pelo discurso da interioridade do arquivo moderno. "Não há arquivo sem exterior" (2001, p. 23), conclui Derrida. Pode não haver arquivo sem exterior, a partir do momento que a epistemologia fronteiriça, por exemplo, valer-se de uma opção descolonial e desobedecer epistemicamente a perspectiva moderna que teima em acreditar ainda como soberana diante das diferenças coloniais e dos discursos outros que grassam no mundo atual. A afirmação de Derrida, de que arquivo é somente uma noção, uma impressão associada a uma palavra e para a qual Freud e nós não temos nenhum conceito. Temos somente uma impressão, uma impressão que insiste através do sentimento instável de uma força móbil, de um esquema ou de um processo infinito ou indefinido ajuda-nos a pensar na prática de uma teorização possível para uma melhor compreensão do arquivo da exterioridade, uma vez que o que acabamos tendo, na verdade, não se trata de um mero discurso acerca da exterioridade, nem muito menos disciplina ou conceitos, mas uma teorização da impressão deixada pelo outro da exterioridade e também pelo crítico, uma impressão biográfica. Tratar de memórias biográficas alheias e de arquivo da exterioridade, tratar de histórias locais, pode ser um meio de o crítico angariar um direito epistêmico de poder falar desse lócus do fora, desse a partir de no qual se encontra tal arquivo, uma vez que ele já está tomado por essa impressão biográfica que, nesse contexto teórico discursivo, já é sua e do outro.

Mignolo distingue claramente teorias pós-coloniais de teorização pós-colonial: enquanto aquelas são vistas como uma mercadoria acadêmica (assim como as teorias pósmodernas), estas são críticas incluídas na razão subalterna e na gnose liminar: "um processo de pensamento que os que vivem sob a dominação colonial precisam empreender para negociar suas vidas e sai condição subalterna" (MIGNOLO, 2003, p. 145-146), afirma o autor. Aqui estou tão somente querendo pensar tal teorização como uma prática, ou opção, para melhor pensar acerca do arquivo da exterioridade. Na sequência, conclui Mignolo:

[...] a teorização subalterna, enquanto ação específica da razão subalterna, coexiste com o próprio colonialismo como uma caminhada e um esforço contínuos em direção à autonomia e à libertação em todas as esferas da vida, da economia à 
religião, da língua à educação, das memórias à ordem espacial.” (MIGNOLO, Histórias locais\Projetos globais ANO, p. 146)

Vejamos que o autor está dizendo que por meio da teorização podemos pensar numa autonomia e libertação das memórias das narrativas (como as de Silviano Santiago) e dos sujeitos da exterioridade, teorização esta que pode ser correlata a uma prática de desarquivamento crítico. No bojo da discussão aqui buscada, vale a pena me deter também nos conceitos de razão subalterna e gnose liminar, ambos trabalhados pelo autor de Histórias locais $\backslash$ Projetos globais (2003) e fundamentais para a ancoragem de um discurso da exterioridade e abertura desse arquivo. Antes de tudo, talvez não seja demais lembrar que estou embasado nos postulados da Crítica biográfica fronteiriça que, mesmo valendo-se dos conceitos advindos da teoria pós-colonial e os da crítica biográfica, parte da premissa da reinserção do bios e do lócus no cerne de sua discussão. A ideia central é a de que para tratarmos da condição mesma do arquivo da exterioridade, ou melhor, para abrirmos esse arquivo, é necessário passarmos por essa discussão conceitual (esses conceitos) que ancora o que Mignolo denomina de teorização pós-colonial, e que aqui prefiro chamar de teorização bios-fronteiriça.

Na esteira do que propõe e defende Mignolo, o aparecimento de novas práticas teóricas vem emergindo depois do final do século 20, sobretudo, “[...] devido à configuração do pensamento crítico subalterno, tanto como prática de oposição na esfera pública quanto uma transformação teórica e epistemológica na academia. (MIGNOLO, 2003, p. 139). É nesse sentido que a razão subalterna ou pós-ocidental, em contraposição à razão ocidental moderna, é entendida como "um conjunto diverso de práticas teóricas emergindo dos e respondendo aos legados coloniais na interseção da história euro-americana moderna." (MIGNOLO, 2003, p. 139) (Grifos do autor). Tal conceito, por sua vez, está preso ao pensamento liminar, ou à gnose liminar, sobre o qual tratarei na sequência. Quero entender que a razão subalterna, enquanto uma prática teórica fronteiriça, ajuda-nos numa reconceitualização dos conceitos, bem como as narrativas e as memórias históricas cristalizadas na cultura. A razão subalterna, mais do que uma prática teórica, é uma opção, uma escolha da qual o crítico fronteiriço se vale para descolonizar o que fora conceitualmente conceitualizado no mundo. Nessa direção, Mignolo reitera que a:

[...] razão subalterna é aquilo que surge como resposta à necessidade de repensar e reconceitualizar as histórias narradas e a conceitualização apresentada para dividir o mundo entre regiões e povos cristãos e pagãos, civilizados e bárbaros, modernos e pré-modernos e desenvolvidos e subdesenvolvidos, todos ele projetos globais mapeando a diferença colonial. (MIGNOLO, 2003, p. 143) 
Surge também como resposta a qualquer ideia moderna, totalizante e abstrata no tocante a uma separação sujeito e objeto, bem como a uma supremacia discursiva, teórica e conceitual advinda de dentro do sistema do pensamento moderno para a exterioridade, reforçando, assim, uma prática teórica cega. Não é à toa que, com relação a isso, Mignolo vai insistir na importância de o crítico se inscrever com sua experiência em sua prática teórica reflexiva. Logo, sem tal inscrição enunciativa discursiva, o crítico não articularia uma teorização bios-fronteiriça. Aqui, mais uma vez, não tenho como não me lembrar do modo único, biográfico e histórico, por meio do qual o intelectual brasileiro Silviano Santiago se inscreve (inscreve seu corpo e sua voz) em suas narrativas biográficas da memória. Conscientemente desse seu papel, o crítico, se, por um lado, não deixa de revisitar criticamente a tradição, por outro lado, não endossa simplesmente o que aquela tradição fez questão de selecionar, escolher, julgar e priorizar como melhor para sua história. Sem querer me deter aqui na questão, o fato é que a narrativa biográfica da memória trabalhada por Silviano dá-se na exterioridade do pensamento da boa tradição literária brasileira, exterioridade essa de fundo subalterno, exterioridade homobiográfica. Valendo-se de uma prática teórica e ficcional que sustenta a razão subalterna, o crítico brasileiro, por meio de sua narrativa memorialística homobiográfica, partilha da prática daqueles intelectuais que "se opõem ao conceito racional e asséptico de teoria e conhecimento" (MIGNOLO, 2003, p. 157), assim como do conceito de literatura moderna, e narra/teoriza não apenas a partir de sua condição de escritor periférico/fronteiriço e homossexual, como também, e por conseguinte, da condição dos personagens homossexuais, marginais, terceiro-mundistas que povoam sua narrativa do bios. Percebo, por meio de sua narrativa memorialística homobiográfica, que o intelectual Silviano acaba por reinscrever na história da tradição literária e cultural brasileira o lado sombrio, reprimido, de uma realidade negada brasileira que ficou literalmente de fora, no esquecimento, da boa tradição/razão literária moderna que imperou no Brasil, por conta talvez, sobretudo, do velho costume que reinou e alimentou tal narrativa hegemônica e falocêntrica de uns poucos falarem por muitos outros. Percebo que a missão civilizadora, educadora, messiânica e salvífica que ancorou a base da boa tradição literária brasileira resguardou para si o direito de falar e de julgar pelo outro, o não civilizado, o ignorante, o excluído, o bárbaro (o negro, o indígena, o fronteiriço, o homossexual etc.) e, por conseguinte, produziu um discurso teórico e ficcional que simplesmente negou, deixou de fora, relegou para a exterioridade aqueles não contemplados. A saída teórica estratégica, e isso a teorização pós-colonial mostra muito bem, assim como o pensamento homobiográfico de Silviano ilustra, é pensar, ou se predispor a pensar, "a partir da fronteira e sob a perspectiva 
da subalternidade.” (MIGNOLO, 2003, p. 159). Na esteira do que propõe Mignolo, entendo que Silviano pensa e escreve não a partir de conceitos, teorias e modelos modernos, mas, sim, a partir daquelas perspectivas anônimas de pensamentos outros que foram silenciadas, relegadas ao esquecimento pela boa prática de absorver, misturar e transformar imperada aqui dentro pela teoria moderna. Rompe, assim, com a tradição moderna e, por meio de tal prática, aproxima-se de todos aqueles mais esquecidos e ignorados que, dentro do Brasil, pensam "[...] a partir das e sobre as fronteiras internas que atravessam as bordas do país (MIGNOLO, 2003, p. 160), mesmo quando (por conseguinte, importando menos) o país, apesar de sua vastidão territorial, seja considerado menor e lançado na exterioridade através do olhar imperial (economicamente) dos grandes centros desenvolvidos do mundo atual. Por meio de sua escrita da memória homobiográfica, Silviano não apenas se situa num lócus geoistórico específico como pensa (a si e ao outro) a partir da "sua" experiência de homossexual/subalterno, podendo, por conseguinte, falar e escrever acerca dessa forma de subalternidade ainda pouco discursivisada dentro da tradição (e da cultura) literária brasileira. Quero entender que pensar a partir de uma experiência homossexual, terceiro-mundista, fronteiriça, brasileira e do sul faz toda a diferença no bojo dessa discussão. Afirma o autor de Histórias locais/Projetos globais que

[...] Pensar a partir de experiências subalternas deve contribuir tanto para a autocompreensão quanto para as políticas públicas, que criam condições para transformar (e estigmatizar) as relações de subalternidade. (MIGNOLO, 2003, p. 160)

Quando um intelectual como Silviano, se vale de uma teorização biográfica fronteiriça, não apenas reforça a prática da razão subalterna de que é possível se pensar das margens, como também, por deter-se em questões da ordem de sensibilidades locais, biográficas e de gêneros, abre uma fissura no próprio pensamento teórico e ficcional viabilizando que, assim, aqueles sujeitos da exterioridade (exclusão) pelo saber moderno passem a ter direitos (epistêmicos). É nessa direção que entendo a afirmação de Mignolo:

[...] as práticas teóricas pós-coloniais não estão apenas mudando nossas visões dos processos coloniais, mas, ao estabelecer ligações epistemológicas entre locais geoistóricos e produção teórica, estão também desafiando as próprias bases do conceito ocidental de conhecimento e compreensão. (MIGNOLO, 2003, p. 165)

Daí eu mesmo constatar, tendo por base o projeto intelectual de Silviano, e pensando aqui na proposta maior que sustenta a teorização da crítica biográfica fronteiriça que une bios e lócus (biolócus), que pelo fato de as narrativas da memória homobiográfica do intelectual agregarem em seu único lócus diferencial de enunciação locais geoistóricos e biográficos, sensibilidades locais e biográficas amalgamadas ao seu modo de teorização posto em prática, elas põem sub judice o direito discursivo da razão moderna ( estou pensando mais na razão 
da tradição literária moderna) como única razão possível. Não é por acaso que, de acordo com Mignolo, “[...] diferencial significa aqui um deslocamento do conceito e da prática das noções de conhecimento, ciência, teoria e compreensão articuladas no decorrer do período moderno.” (MIGNOLO, 2003, p. 167). Nesse sentido, não é demais reiterar que as narrativas da memória homobiográficas de Silviano deslocam, sensivelmente, a prática da razão do discurso literário moderno que imperou quase sempre dentro do país, principalmente quando não levou em conta as diferenças coloniais. O discurso biográfico fronteiriço de Silviano, ou melhor, seu projeto homobiográfico fronteiriço se ancora a partir das heranças coloniais do país e, por erigir seu discurso a partir da diferença colonial, acaba por propor uma descentralização das fronteiras internas do país e ajuda-nos a todos a nos compreender como sujeito do sul da exterioridade.

Se até aqui me detive tão somente no conceito de razão subalterna, passo agora ao de gnose liminar, ou pensamento liminar (MIGNOLO, 2003, p. 167) ou fronteiriço, como o prefiro, apesar de entender que aquele conceito está diretamente vinculado ao de gnose liminar. O autor do conceito é Walter Mignolo, que o introduziu e o explicou deste as páginas iniciais de seu livro Histórias locais\Projetos globais (2003) e que aqui o tomo como fundamental para a discussão que venho propondo e que passa pelas narrativas da memória homobiográficas do intelectual brasileiro Silviano Santiago. Na leitura de Mignolo, gnose “é o conhecimento concebido das margens externas do sistema colonial/moderno" (MIGNOLO, 2003, p. 33), enquanto gnosiologia liminar “[...] é uma reflexão crítica sobre a produção de conhecimento, a partir tanto das margens internas do sistema mundial colonial/moderno [..] quanto das margens externas.” (MIGNOLO, 2003, p. 33). Penso, com base no exposto, que mais uma vez o projeto do intelectual brasileiro ilustra sobremaneira a discussão proposta, uma vez que, se por meio de sua literatura ficcional Silviano concebe uma literatura da exterioridade, tendo o país e a língua dentro de um projeto mundial global altamente excludente (daí a exterioridade), já por meio de sua gnosiologia fronteiriça brasileira/latina Silviano empreende uma teorização que desbarata a lógica do conhecimento moderno. Apesar da aparente dualidade que exponho, reitero que a literatura do escritor não é em nada menos teórica, sendo, na verdade, uma extensão de sua teorização biográfica. A exemplo disso, basta ver as narrativas de Em liberdade (1981), O falso mentiroso (2004) e Mil rosas roubadas (2014), entre outros. Pensando na produção literária de Silviano, e tendo por base a gnose liminar, ou gnose fronteiriça, entendo que a proposta do projeto do intelectual não descarta, digamos, a epistemologia moderna, antes, e pelo contrário, dialoga com ela, mas sempre se construindo a partir dos saberes outros que foram relegados à exterioridade pelo 
projeto moderno. Ocorre aí, por conseguinte, uma encenação tanto dos sujeitos excluídos, quanto dos saberes fronteiriços. ${ }^{7}$ Quero entender que apesar de Silviano, o intelectual quero dizer, ter uma vivência e uma experiência, um trânsito e uma "formação" na cultura e na literatura europeias e norte-americanas, ele o é um intelectual brasileiro, periférico, latino, fronteiriço, e escrevendo em língua portuguesa; logo, posso dizer que sua teorização ensaística e ficcional está, a partir dessa exterioridade do mundo ocidental, “[...] absorvendo e deslocando formas hegemônicas de conhecimento" (MIGNOLO, 2003, p. 170) sobretudo por meio de sua prática subalterna de trazer o bios, as experiências, as sensibilidades, os afetos e as memórias tanto seus, enquanto intelectual do Sul e homossexual que é, quanto das personagens subalternas; e, desse modo, sua literatura, sobretudo, acaba ajudando a estancar uma "ferida aberta" do preconceito e da exclusão que sangra dentro da cultura do país. É nesse sentido que entendo, aliás, quando Mignolo afirma que "a gnose liminar é um anseio de ultrapassar a subalternidade e um elemento para a construção de formas subalternas de pensar." (MIGNOLO, 2003, p. 140). Assim, o modo como Silviano dialoga com a tradição e, especificamente, o lugar onde ele engasta seu lócus diferencial de enunciação permitem e dão a ele o direito epistêmico de construir e propor uma forma fronteiriça de pensar que vai na contracorrente do modo hegemônico de pensar dentro da tradição literária brasileira.

Depois de passar pelos conceitos de arquivo, razão subalterna e gnose liminar, detenho-me agora no de exterioridade, e o faço trazendo a política do pensamento fronteiriço, por entender que esse conceito encena o campo ("espaço", lê-se na epígrafe a seguir) para a teorização desse pensamento.

\section{Habitar a exterioridade da fronteira}

O problema não é descrever na "realidade" os dois lados da fronteira. O problema é fazê-lo a partir de sua exterioridade (no sentido de Levinas). O objetivo é apagar a distinção entre o sujeito que conhece e o objeto que é conhecido, entre um objeto "híbrido" (o limite como aquilo que é conhecido) e um "puro" sujeito disciplinar ou interdisciplinar (o conhecedor) não contaminado pelas questões liminares que descreve. Para mudar os termos do diálogo, é necessário ultrapassar, por um lado, a distinção entre sujeito e objeto, e, por outro, entre epistemologia e hermenêutica. O pensamento liminar visa ser o espaço no qual se elabore essa nova lógica. (MIGNOLO, 2003, p. 42)

\footnotetext{
7 "Devido a este fato, já está sendo elaborada uma mudança epistemológica importante, segundo a qual a enunciação enquanto encenação assume precedência sobre a encenação enquanto representação'. (MIGNOLO, 2003, p.171)
} 
Habitar a fronteira é habitar a exterioridade. Esta afirmação desbarata aquela ideia moderna de que o sujeito se poria, ou poria o seu pensamento, em um dos lados da fronteira e falaria sobre o outro lado, como se lê no início da epígrafe. Nada disso. A exterioridade, o conceito de exterioridade, se forma e se dá a ver, se não sem uma aparente dualidade, sempre a partir do que fora pensando dentro do sistema do pensamento moderno. Em todo o caso, a questão é mais problemática do que possa parecer. Tanto é verdade que eu mesmo já me detive na discussão acerca de tal conceituação ${ }^{8}$, e se o faço de novo agora é porque quero entender que há muito que ainda precisa ser dito e entendido por todos nós que queremos pensar por fora do pensamento moderno e não mais passando, obrigatoriamente, por ele. Ainda na sequência da epígrafe, quando o autor constata que o problema é descrever os dois lados da fronteira a partir da exterioridade, lembro aqui do próprio Mignolo que, em El vuelco de la razón (2011), afirma que “ [...] a exterioridade não é algo que se pode descrever somente do interior do sistema, mas que requer uma narrativa criada na mesma exterioridade, por quem e quem a habita. (MIGNOLO, 2011, p. 51) ${ }^{9}$ A diferença se instaura porque quem fala da exterioridade, fala a partir da diferença colonial, fala da fronteira. Não é à toa que Mignolo vai nos lembrar que "[...] habitar a diferença colonial é distinto de habitar o discurso que a produziu, mesmo quando se tome uma atitude crítica a esse discurso" (MIGNOLO, 2010, p. 44-45). ${ }^{10}$ Habitar a exterioridade da fronteira salvaguarda um direito epistêmico específico para o sujeito que fala a partir desse lócus. Retomando mais uma vez a epígrafe, vemos que o pensamento fronteiriço se apresenta como o espaço no qual se elabora uma lógica outra, lógica esta da qual emerge a epistemologia fronteiriça. ${ }^{11}$ Esse espaço da exterioridade não se situa nem do lado de cá, nem do lado de lá da fronteira, nem muito menos dentro ou fora, mas, sim, na barra que separa e une o dentro (a interioridade) do fora (a exterioridade). Assim, o discurso da exterioridade se engasta nessa perspectiva outra, a partir da qual só se pode falar a partir dela e nunca sobre ela; não ignora, nem rechaça o pensamento e o discurso modernos migrados dos centros, mas sabe que habita um espaço que não pode ser representado por aquele discurso dos centros. Na esteira de Mignolo, lembro que cada

\footnotetext{
${ }^{8}$ Ver meu texto "A (des)ordem epistemoloógica do discurso fronteiriço", p. 47-65, especificamente a parte intitulada "A exterioridade do dentro (fora), compreendida entre as páginas 61-64. In: CADERNOS DE ESTUDOS CULTURAIS: Ocidente/Oriente: migrações (2016).

9 "la exterioridad no es algo que se pueda describir sólo desde el interior del sistema (como tan bien hace Wallerstein) sino que requiere uma narrativa creada em la misma exterioridad - por quien y quienes la habitan." (MIGNOLO. 2011 p. 51)

10 "De habitar la exterioridad, surge la epistemologia fronteriza como método del pensar descolonial y las trayectorias de las opciones descoloniales." (MIGNOLO. 2010, p. 44-45)

11 "De habitar la exterioridad, surge la epistemologia fronteriza como método del pensar descolonial y las trayectorias de las opciones descoloniales." (MIGNOLO. Desobediencia epistémica, p. 44-45)
} 
história local, cada narrativa da exterioridade, habita sua própria fronteira, sua própria linguagem, sua própria memória, sua própria ética e sua própria teoria. Nesse sentido, as narrativas da memória homobiográficas de Silviano são exemplar: histórias e memórias de sujeitos subalternos se tecem em paralelo à narrativa biográfica do próprio intelectual. Diante de exemplos como esse, resta à crítica detentora de uma teorização biográfica fronteiriça se por nesse espaço do exterior, não para julgar ou analisar o outro, mas para se aproximar e escutar a teorização emanada do corpo e do discurso desse outro da exterioridade. Cabe aqui uma observação mais do que pertinente de Mignolo, necessária:

[...] cuando hablo de exterioridad (recuérdese) no me refiero a lo que queda fora sino al espacio en el que emergem las tensiones uma vez que el capitalismo se convierte en el sistema económico dominante y elimina toda posibilidad de que exista algo ajeno a él, pero no de que exista algo exterior a él. (MIGNOLO, 2011, p. 46-47)

Pode não existir nada que fique alheio, ou que passe incólume ao sistema econômico dominante e global, como se vê na passagem acima, mas repito que existe algo exterior a ele. Existem pessoas, lugares outros, discursos, saberes e ignorâncias que sobrevivem em sua condição de exterioridade, ou de fronteiridade. Vidas habitam as fronteiras ignoradas. Como nas narrativas da memória homobiográficas de Silviano, dentro das quais o espaço do discurso narrativo encena sujeitos subjugados que representam discursos negados que vão se reinscrevendo na cultura (sendo escutados), também vivo, trabalho e escrevo a partir de um lugar denominado de fronteira-sul: a partir do qual todos devemos revoltar-nos contra a imposição das teorias modernas itinerantes que teimam em querer nos manter a todos na borda do fora, como uma mera extensão de seu corpo cuja cabeça se mantêm no centro (Norte). Pensar a partir da fronteira-sul nos situa nessa borda do país que faz divisa com outros lugares, outras exterioridades completamente ignoradas pelos centros e pelo poder discursivo, social e econômico que esses centros políticos fazem questão de manter, ignorando a diferença colonial que grassa na exterioridade. A fronteira-sul, enquanto espaço da exterioridade e lugar fronteiriço por excelência, é a morada da Revolta, da ignorância e do abandono de toda sorte e ao deus-dará. Nesse espaço que compreende o pântano e o cerrado do Oeste, talvez somente um pensamento pós-abissal como o defendido por Boaventura de Sousa Santos, em Epistemologias do Sul (2010), seja capaz de contorná-lo desde dentro de sua exterioridade e ignorância sem fim.

Sousa Santos entende o pensamento moderno como um pensamento abissal, enquanto que todo aquele pensamento considerado não-moderno seria entendido como pós-abissal. Nesse sentido, vale a pena transcrever a primeira nota de seu texto que nos parece esclarecedora a respeito: 
Não pretendo que o pensamento moderno ocidental seja a única forma de pensamento abissal. Pelo contrário, é muito provável que existam, ou tenha existido, formas de pensamento abissal fora do Ocidente. Não é meu propósito analisá-las neste texto. Defendo apenas que, abissais ou não, as formas de pensamento nãoocidental têm sido tratadas de um modo abissal pelo pensamento moderno ocidental. Também não trato aqui do pensamento pré-moderno ocidental nem das versões do pensamento moderno ocidental marginalizadas ou suprimidas por se oporem às versões hegemônicas, as únicas de que me ocupo neste ensaio (SANTOS apud SANTOS; MENESES, 2010, p. 31).

$\mathrm{O}$ autor se detém apenas nas versões hegemônicas do pensamento moderno ocidental, como se lê na passagem, para se deter, depois, na pensamento pós-abissal, ou seja, aquele pensado a partir da fronteira, ou melhor, da exterioridade. Assim como a exterioridade não existe sem a interioridade, o pensamento pós-abissal não existe sem o pensamento abissal, aliás, aquele foi criado por este, que consiste, segundo o autor, em distinções invisíveis (e visíveis) que "são estabelecidas através de linhas radicais que dividem a realidade social em dois universos distintos: o universo 'deste lado da linha' e o universo 'do outro lado da linha"”. (SANTOS apud SANTOS; MENESES, 2010, p. 31-32). O pensamento "deste lado da linha" equivale ao pensamento moderno, ao pensamento colonial, da interioridade (do centro); enquanto o pensamento "do outro lado da linha" equivaleria ao pensamento fronteiriço (descolonial), da exterioridade. O problema nesse jogo dualista é que tudo aquilo que é excluído do universo (Universal) “[...] deste lado da linha” torna-se simplesmente inexistente e é produzido como inexistente: "inexistência significa não existir sob qualquer forma de ser relevante ou compreensível" (SANTOS apud SANTOS; MENESES, 2010, p. 32), afirma Sousa Santos; que arremata: “[...] tudo aquilo que é produzido como inexistente é excluído de forma radical porque permanece exterior ao universo que a própria concepção aceite de inclusão considera como sendo o Outro.” (SANTOS apud SANTOS; MENESES, 2010, p. 32). A discussão feita por Sousa Santos acerca do pensamento abissal X pensamento pós-abissal acentua a origem, ou fundação mesma do lócus fundante da exterioridade, bem como o lugar onde se encontra esse sujeito Outro da exterioridade, da exclusão. Evidencia-se por meio da discussão feita o quanto o pensamento deste lado da linha reforça a não existência do outro lado da linha, reforçando, por conseguinte, além da inexistência do outro e do mundo (lócus) desse outro, sua invisibilidade. O outro de fora é criado pelo outro de dentro para fundar a visibilidade deste e o apagamento, o esquecimento, a exclusão sumária daquele. O poder, a capacidade de produzir e radicalizar distinções move de tal forma o pensamento deste lado da linha que ele simplesmente rasura, ou melhor, torna invisível a linha abissal na qual se funda. Por conseguinte, tudo o que é da ordem do visível, do pensável, que estrutura a realidade social vigente (deste lado da linha), dá-se a partir da invisibilidade do outro lado da linha. É exatamente por isso que Sousa Santos é levado a concluir que "[...] a 
característica fundamental do pensamento abissal é a impossibilidade da copresença dos dois lados da linha." (SANTOS apud SANTOS; MENESES, 2010, p. 32). Detentor de um olhar imperial, moderno e castrador (binário), o pensamento abissal, por consistir na distinção universal entre o verdadeiro e o falso ( penso aqui na idéia de uma estética abstratizante), acentuou a disputa entre as formas científicas e não-científicas da verdade, defendendo, por conseguinte, sua visibilidade quanto à forma do conhecimento moderno, ignorando, por sua vez, ou relegando à invisibilidade, outras formas de conhecimento, como "os populares, leigos, plebeus, camponeses, ou indígenas do outro lado da linha" mencionados por Sousa Santos.

A fronteira-sul aqui em questão, metaforicamente, ilustra exemplarmente o outro lado da linha de que fala Sousa Santos. Um mundo da ignorância se erige e se esconde do saber acadêmico e disciplinar que ainda grassa deste lado da linha. Se, de acordo com o pensamento moderno (o deste lado da linha), daquele lado da linha não há conhecimento, nem produção de saberes e nem muito menos de teorias, há, com certeza crenças indígenas, dialetos, línguas outras como o Portunhol selbaje (DIEGUES, 2017), que não são meros objetos passíveis de dissecações analíticas. ${ }^{12}$ Quando o discurso moderno, sobretudo o estatal, olha para a paisagem do outro lado da linha que constitui a fronteira-sul, vale-se ainda de uma visada dualista, centrada no legal e no ilegal. Para Sousa Santos:

[...] esta dicotomia central deixa de fora todo um território social onde ela seria impensável como princípio organizador, isto é, o território sem lei, fora da lei, o território do a-legal, ou mesmo do legal e ilegal de acordo com direitos não oficialmente reconhecidos. (SANTOS apud SANTOS; MENESES, 2010, p. 32)

Nesse sentido, a fronteira-sul, enquanto um lugar da legalidade e da ilegalidade, do contrabando e do atravessamento, por onde transitam turistas, andariegos, sul-matogrossenses, bolivianos e paraguaios, entre outros divíduos, funda o que aqui vimos chamando de exterioridade. O discurso da lei, o discurso moderno da teoria, o discurso do saber moderno fundam o discurso visível que impera e que reforça uma invisibilidade aparente. $\mathrm{O}$ outro lado da linha existe tão somente para reforçar a visibilidade do discurso deste lado da linha. Nessa direção, do outro lado da linha continua não havendo vida, realidade, saberes e teorias possíveis, muito menos indivíduos e, por conseguinte, representações. Um mundo do assombro, do anonimato, da escuridão se sucumbe ao esquecimento letal do outro lado da linha. A douta ignorância (Sousa Santos) não vê a ignorância que resiste e sobrevive do outro lado da fronteira-sul. (Nas últimas linhas deste texto tratarei da questão da douta ignorância discutida por Sousa Santos). Não é à toa que o outro lado da linha, a fronteira-sul, a

\footnotetext{
${ }^{12}$ Ver nesse sentido o livro Triple frontera dreams (2017), de Douglas Diegues.
} 
exterioridade, o Sul global, não passa de espaço enquanto uma imensidão perdida onde experiências locais e biográficas são desperdiçadas, ignoradas, assim como seus divíduos, cuja localização territorial, segundo Sousa Santos, coincide com a zona colonial: “[...] tudo o que não pudesse ser pensado em termos de verdadeiro ou falso, de legal ou ilegal, ocorria na zona colonial." (SANTOS apud SANTOS; MENESES, 2010, p. 35). O colonial, e aqui pensando como a fronteira-sul, representa o "sem lei", lugar de bárbaros e selvagens, onde não reina o saber e nem muito menos a teoria, enfim, o lugar da natureza por excelência. “[...] Assim, uma vasta região do mundo em estado de natureza se cria, onde se refugiam os condenados da terra" (FANON), os condenados da fronteira (NOLASCO), reforçando, por conseguinte, a inexistência do estado de natureza, onde um mundo invisível se forma:

[...] o universo das crenças e dos comportamentos incompreensíveis que de forma alguma podem considerar-se conhecimento, estando, por isso, para além do verdadeiro e do falso. $\mathrm{O}$ outro lado da linha alberga apenas práticas incompreensíveis, mágicas ou idolátricas. A completa estranheza de tais práticas conduziu à própria negação da natureza dos seus agentes." (SANTOS apud SANTOS; MENESES, 2010, p. 37)

É nesse sentido, ainda segundo o autor, que a exclusão gerada torna-se inexistente, já que os sub-humanos não são sequer candidatos à inclusão social: "a humanidade moderna não se concebe sem uma sub-humanidade moderna. (SANTOS apud SANTOS; MENESES, 2010, p. 39)

Foi essa divisão abissal criada entre mundo humano do sub-humano que estabeleceu o que aqui estamos chamando de exterioridade. E constatamos, de fato, que sem esse lado da linha, não haveria o outro lado da linha, ou seja, vida na/da exterioridade. De acordo com Sousa Santos, foi essa negação sacrificial da humanidade de quem estava do outro lado da linha por quem estava desse lado da linha que estabeleceu e afirmou essa parte da humanidade como universal. Hoje, mais do que nunca, negar a exterioridade é equivalente a negar o mundo da exclusão que grassa no mundo. E povos sub-humanos, bárbaros e selvagens, geram, por conseguinte, teorias desacreditadas e inconsistentes. Nesse sentido, somente uma teorização que emirja dessa teorização fronteiriça poderia alcançar aqueles que se encontram na borda do fora. Reiterando a ideia de que foram os povos que se encontravam do outro lado da linha que se levantaram contra toda e qualquer exclusão radical, e aqui pensando na teorização da exterioridade que também rechaça a teoria moderna gerada no centro, que podemos pensar e afirma que somente uma teoria que nasça desse lócus fronteiriço pode e deve tratar com mais propriedade dessa questão que vem envolta a esse mundo da exclusão. Nesse sentido o que Walter Mignolo afirma sobre a conceituação de uma teorização bárbara é fundamental: 
[...] uma prática teórica daqueles que se opõem ao conceito racional e asséptico de teoria e conhecimento, teorizando, precisamente, a partir da situação na qual forma colocados, seja, eles judeus, muçulmanos, ameríndios, africanos ou outros povos do 'Terceiro Mundo', como os hispânicos nos Estados Unidos de hoje. (MIGNOLO, 2003, p. 158)

Tal teorização é mais bem posta em prática quando o crítico tem consciência de que sua inscrição enquanto crítico ou teórico fronteiriço em sua teorização é necessária, como reitera Mignolo. A experiência fronteiriça do sujeito pensante está na base da sua reflexão crítica, engastando e pontuando a origem de seu discurso crítico subalterno a partir dessa exterioridade que se faz presente por meio enunciativo do fora. Esse lócus fronteiriço, de acordo com o que propõe Mignolo, não é apenas geográfico, mas histórico e principalmente epistemológico. Daí caber ao crítico, por meio dessa sua teorização pós-ocidental, ou, como prefiro, fronteiriça, "reinscrever na história da humanidade o que foi reprimido pela razão moderna, em sua versão de missão civilizadora ou em sua versão de pensamento teórico negado aos não-civilizados.” (MIGNOLO, 2003, p. 158). O que fora reprimido, ou excluído, se encontra na condição de exterioridade. Logo, é preciso que se defenda, como faz Mignolo, que se pense a partir da fronteira, e pensar a partir da fronteira aqui é correlato a pensar $a$ partir do conceito moderno de teoria:

\begin{abstract}
Pensar teoricamente é dom e competência de seres humanos, não apenas de seres humanos que vivam em um certo período, em certos locais geográficos do planeta e falem um pequeno número de línguas específicas. Se a pós-colonialidade não consegue romper com a epistemologia moderna, torna-se apenas outra versão dela, com um tema diferente. Seria, em outras palavras, uma teoria sobre um assunto novo, mas não a constituição de um novo sujeito epistemológico que pensa a partir das e sobre as fronteiras. (MIGNOLO, 2003, p. 159)
\end{abstract}

A aparente dualidade entre o pensamento abissal e o pós-abissal trabalhados por Sousa Santos, e que aqui embasam minha discussão, somam-se à discussão proposta por Mignolo acerca da Modernidade e Contramodernidade, teoria moderna e teorização pós-colonial, sobretudo no tocante à possibilidade de uma outra forma de compreender o mundo e a consciência crítica e filosófica de que as teorias também produzem-se e vivem do outro lado da linha, na exterioridade, e não somente no centro da razão ocidental moderna. Um dos méritos da teorização fronteiriça é que ela traz para o plano da discussão teórica as sensibilidades locais e biográficas do crítico e do sujeito do lugar, assim como a importância da localização de onde tal teorização está sendo feita; “[...] a devolução da sensibilidade e da localização à teorização pós-colonial confere poder àqueles que foram eliminados ou marginalizados da produção do saber e do entendimento." (MIGNOLO, 2003, p. 165) (Aqui abro outro parêntese para lembrar e dizer que toda a literatura da memória homobiográfica de Silviano Santiago, mesmo reconhecendo que o escritor e crítico inventa a partir de um diálogo fundante com a tradição cultural, não pode ser melhor compreendida se não se levar em conta 
que a origem de seu discurso outro (e não moderno) está preso aos loci diferencials de enunciação da exterioridade. ${ }^{13}$ Quero entender que a proposta do projeto do escritor detentor de um discurso memorialístico homobiográfico traz em sua base um arranjo, ou encenação enunciativa que desbarata a falácia eurocêntrica (DUSSEL), apregoada pelo projeto da modernidade (falocêntrica). Ainda pensando sobre a produção intelectual de Silviano, quero entender que, mais do que simplesmente dialogar com a tradição literária e cultural, sua proposta dessubalterniza a própria tradição cultural e literária, dessubalterniza a teoria, por meio de uma prática plurilógica e pluritópica que, de acordo com o que propõe Mignolo, contribui para a subversão da velha proposta comparatista das semelhanças-e-diferenças para as semelhanças-na-diferença. ${ }^{14} \mathrm{E}$ é nesse sentido que entendo que a proposta do projeto político-literário-teórico-cultural de Silviano erige-se como uma proposta descolonial fronteiriça e subverte pelo avesso o sistema colonial do pensamento moderno (sobretudo o literário). Por meio de seu discurso, o intelectual, valendo-se da pratica das semelhanças-nadiferença, traz para a superfície do discurso indivíduos marginalizados (homossexuais, por exemplo) e teorias biográficas que se encontram nos entrelugares e que passam a ser tratados, compreendidos e lidos não mais apenas no sentido de desconstruídos mas, sim, no de descolonizados. É nesse sentido que a narrativa da memória homobiográfica de Silviano descoloniza a escrita literária, os discursos teóricos e críticos e a própria leitura da literatura. A presença do bios e suas nuanças e história faz toda a diferença na estratégia ficcional e teorização crítica descolonial defendidas por Silviano. O homo e o transs- que se encontram no corpo e na herança do intelectual levam-no a ultrapassar descentralizando e deslocando tudo o que aprendeu, leu e viveu).

Enquanto Mignolo afirma que "se a pós-colonialidade não consegue romper com a epistemologia moderna, torna-se apenas outra versão dela" (MIGNOLO, 2003, p. 159), Sousa Santos, ao tratar do pensamento pós-abissal, também nos adverte que "o reconhecimento da persistência do pensamento abissal é, assim, a conditio sine qua non para começar a pensar e a agir para além dele.” (SANTOS apud SANTOS; MENESES, 2010, p. 52). Pensar para além do pensamento abissal significa pensar a partir do outro lado da linha, a partir da exterioridade, a partir da fronteira-sul aqui em questão. $\mathrm{O}$ que ambos os críticos afirmam corrobora a idéia de que não se trata de simplesmente desconstruir o pensamento moderno, ou de pensar a epistemologia fronteiriça a partir das boas intenções da

13 “...eu optei por um determinado tipo de literatura, em que eu me salvo de minha imaginação enlouquecida. Eu trabalho com a tradição, mas com uma imaginação enlouquecida, rebelde, uma imaginação de hipertensão cardíaca", p. 41 (Entrevista "Silviano, o equilibrista", feita por José Castello, 2018)

${ }^{14}$ Ver MIGNOLO. Histórias locais/Projetos globais, p. 278. 
epistemologia moderna. Trata-se, antes, de uma desobediência epistêmica (MIGNOLO), ou uma ruptura radical (SANTOS) com relação ao pensamento moderno ocidental. Sem o reconhecimento de que fala Santos, sem agir de modo desobediente epistemologicamente como propõe Mignolo, optando por uma opção descolonial, o crítico permanece dentro do pensamento derivativo, ou epistemologia moderna, reproduzindo as linhas de força abissais desse pensamento, e isso não basta para criar um pensamento pós-abissal (SANTOS), ou pensamento descolonial (MIGNOLO); antes, é preciso, como propõe Santos, propor uma "[...] ruptura radical com as formas ocidentais modernas de pensamento e ação." (SANTOS, 2010, p. 20). Não basta se propor a pensar a exterioridade deste lado da linha; é preciso se por a pensá-la a partir do outro lado da linha. O pensar a partir de tão defendido por Mignolo em Histórias locais/Projetos globais faz toda a diferença nessa discussão conceitual e epistemológica. Pensar a partir de o impensável, situando:

[...] a nossa perspectiva epistemológica na experiência social do outro lado da linha, isto é, do Sul global não-imperial, concebido como a metáfora do sofrimento humano sistêmico e injusto provocado pelo capitalismo global e pelo colonialismo. (SANTOS apud SANTOS; MENESES, 2010, p. 52)

A opção descolonial que sustenta a desobediência epistêmica que rege a epistemologia fronteiriça nos ensina que "[...] somente aprendemos com o Sul usando uma epistemologia do Sul (SANTOS, 2010, p. 52)", como defende Santos ao introduzir o conceito de um pensamento pós-abissal. Isso é correlato a falar da exterioridade de fora dela, ou seja, da interioridade, ou do centro, como tão comumente fez e faz o pensamento do dentro. Apesar do vínculo entre o dentro e a exterioridade, epistemologicamente, só a aferimos, discursivamente falando, quando nos propomos a pensar a partir dela, e não o contrário. É nesse sentido que todos os defensores de uma visada pós-colonial são taxativos quanto ao modo de se pensar a descolonialidade. Entre tais condições essências, Sousa Santos adverte que "[...] a primeira condição para um pensamento pós-abissal é a copresença." (SANTOS apud SANTOS; MENESES, 2010, p. 53). A copresença implica uma relação direta entre os sujeitos e as práticas de ambos os lados da fronteira, tomando-os numa simultaneidade contemporânea, abolindo, por conseguinte, a concepção linear de tempo, afirma Boaventura. Daí o pensamento pós-abissal, enquanto uma ecologia dos saberes, defender “"[...] a ideia da diversidade epistemológica do mundo, o reconhecimento da existência de uma pluralidade de formas de conhecimento além do conhecimento científico". (SANTOS apud SANTOS; MENESES, 2010, p. 54). Por ser uma contra-epistemologia, a ecologia dos saberes com seu pensamento-abissal é atravessada tanto por conhecimentos quanto por ignorâncias. Essa ambivalência, longe de qualquer unidade, pontua, segundo Boaventura, que ambas as formas 
de conhecimento ou de ignorância são heterogêneas e interdependentes. Nessa relação, o autor lembra-nos de que quando tomamos conhecimento de algo, quase sempre também esquecemos, ignoramos outros conhecimentos. No contexto de uma ecologia dos saberes, “[...] a ignorância só é uma forma desqualificada de ser e de fazer quando o que se aprende vale mais do que o que se esquece." (SANTOS apud SANTOS; MENESES, 2010, p. 54). Com base no que Boaventura propõe e defende, e pensando aqui na exterioridade por nós perseguida, diríamos que ela pode ser uma ignorância de quem não a conhece por não saber de sua existência o que seria utópico no contexto do mundo atual global), ou seria uma "douta ignorância" por parte daquele "que sabe que ignora e o que ignora." Mas a acepção de douto ignorante em nosso tempo pode ter um sentido muito diferente, de acordo com Boaventura: “[...] ser um douto ignorante no nosso tempo é saber que a diversidade epistemológica do mundo é potencialmente infinita e que cada saber só muito limitadamente tem conhecimento dela." (SANTOS apud SANTOS; MENESES, 2010, p. 54). Segundo o autor, a douta ignorância antes mencionada é única, enquanto a de nosso tempo seria infinitamente plural. Boaventura se detém longamente sobre o assunto em seu texto "Um ocidente nãoocidentalista? A filosofia à venda, a douta ignorância e a aposta de Pascal". ${ }^{15}$ Aqui só me interessa pensar sobre a douta ignorância tendo por base a exterioridade entendida enquanto um Sul global que foi ignorado pelo Norte global. Valendo-se de uma opção descolonial e de uma desobediência epistêmica, o pensamento do Sul, isto é, da exterioridade, ignora a ignorância do pensamento moderno sobre os saberes e as experiências do Sul e des-pensando e saprendendo (desobedecendo) reinventa e reabilita todo aquele conhecimento que fora ignorado pelo pensamento abissal moderno. É nesse sentido que Boaventura conclui que “[...] a douta ignorância é uma luta contra a ignorância ignorante do Norte global em relação ao Sul global." (SANTOS apud SANTOS; MENESES, 2010, p. 557). Nesse sentido, a epistemologia fronteiriça que emerge da fronteira-Sul, da exterioridade, ou do outro lado da linha ajudamnos a barrar a ignorância ignorante do pensamento moderno que não fez outra coisa senão fundar um mundo da exterioridade para ser melhor dominado e, por extensão, excluído. Com base nessa epistemologia que se funda a partir de um lugar específico no espaço, os teóricos, críticos, ou escritores como Silviano Santiago, todos, enfim, que ancoram seu pensamento "num profundo exercício de autorreflexividade" (SANTOS apud SANTOS; MENESES, 2010, p. 27), têm consciência da possibilidade da escolha, assim como eu mesmo estou tendo

\footnotetext{
${ }^{15}$ Ver SANTOS; MENESES (org.). Epistemologias do Sul, p. 519-562.
} 
agora quando leio, penso e escrevo que a exterioridade se converteu numa questão para mim. ${ }^{16}$

\section{Referências}

DERRIDA, J. Mal de arquivo. Trad. de Cláudia de Moraes rego. Rio de Janeiro: Relume Dumará, 2001.

MIGNOLO, W. Habitar la frontera: sentir y pensar la descolonialidad (antología, 19991014) Barcelona: CIDOB, 2015.

MIGNOLO, W. Histórias locais/Projetos globais. Trad. de Solange Ribeiro de Oliveira. Belo horizonte: Editora UFMG, 2003.

MIGNOLO, W. Desafios decoloniais hoje. Trad. de Marcos de Jesus Oliveira. Epistemologias do Sul, foz do Iguaçu/PR, 1 (1), PR. 12-32, 2017.

MIGNOLO. W. Desobediência epistêmica: a opção descolonial e o significado de identidade em política. Trad. de Ângela Lopes norte. Cadernos de letras da UFF - Dossiê Literatura, Língua e identidade, n.34, p. 287-324, 2008.

MIGNOLO. W. El vuelco de la razón. Buenos Aires: Del Signo, 2015.

NOLASCO, E. C. A (des)ordem epistemológica do discurso fronteiriço, p. 47-66. In: CADERNOS DE ESTUDOS CULTURAIS: ocidente/oriente: migrações. Campo Grande, vol.8, n.15, jan./jun. 2016.

NOLASCO, E. C. Memórias subalternas latinas: ensaio biográfico, p. 130-159. In: NOLASCO, E.C. Perto do coração selbaje da crítica fronteriza. São Carlos: Pedro \& João Editores, 2013.

SANTIAGO, S. Silviano, o equilibrista. ENTREVISTA por José Castello. In: REVISTA OLYMPIO: literatura e arte. Belo Horizonte, maio de 2018, n.1. p .37-43.

SANTOS, B. de S. Para além do pensamento abissal: das linhas globais a uma ecologia dos saberes, p. 31-83. IN: SANTOS, B. de S.; MENESES, M. P. (org.) Epistemologias do Sul. São Paulo: Cortez, 2010.

SANTOS, B. de S. Um ocidente não-ocidentalista? A filosofia à venda, a douta ignorância e a aposta de Pascal, p.519-562. IN: SANTOS, B. de S.; MENESES, M. P. (org.) Epistemologias do Sul. São Paulo: Cortez, 2010.

\footnotetext{
${ }^{16}$ Sugiro que se leia o último parágrafo do texto de Boaventura, intitulado "Para além do pensamento abissal: das linhas globais a uma ecologia de saberes", p. 66.
} 